\title{
Pregnant transmen and barriers to high quality healthcare
}

\author{
Anthony P. Berger, MPH, ${ }^{1}$ Elizabeth M. Potter, ARNP, CNM ${ }^{2}$ Christina M. Shutters, \\ ARNP, CNM, ${ }^{2}$ Katherine L. Imborek, MD ${ }^{3}$
}

Keywords: Prenatal care, perinatal care, postpartum care, trans*, transgender, transmen, pregnancy, obstetrics

\begin{abstract}
A transman presents for prenatal care with a planned, desired pregnancy and no underlying medical issues. Clinicians caring for him are initially unable to initiate a pregnancy episode in the electronic medical record (EMR) secondary to his legal designation as male, and must change the gender marker in the EMR to female in order to document the pregnancy. This situation illuminates the systemic challenges faced by transmen seeking health care, especially in the area of obstetrics. This article will review language used to define the trans* community, highlight trans* healthcare disparities, review the context in which transmen receive perinatal care, discuss what is known about their experiences, and make recommendations for improvement in healthcare systems to eliminate barriers to safe, effective, and culturally-competent care.

${ }^{1}$ University of lowa, Roy J. and Lucille A. Carver College of Medicine, lowa City, lowa

${ }^{2}$ University of lowa Hospitals and Clinics, Department of Obstetrics and Gynecology, lowa City, lowa

${ }^{3}$ University of lowa Hospitals and Clinics, Department of Family Medicine, lowa City, lowa
\end{abstract}

\section{The Trans* Community}

\section{Defining the Trans* Population}

Trans* is an all-inclusive term that captures any individual with an internal gender identity that differs from the sex they were assigned at birth. These individuals can identify as the "opposite" gender (i.e., man or woman), as agender (i.e., genderfree, non-gender, genderless, or ungendered), as multiple genders (i.e., bigender or pangender), or as fluctuating genders (i.e., genderfluid or genderqueer). Many of these identities have recently evolved in conjunction with a greater societal understanding that gender identities fall along a spectrum, as opposed to a strict binary (female versus male). ${ }^{1}$ Cisgender individuals, conversely, are those whose internal gender identity is congruent with the sex they were assigned at birth.

Transmen are defined as individuals who were assigned the female sex at

Please cite this paper as: Berger AP, Potter EM, Shutters CM, Imborek KL Pregnant transmen and barriers to high quality healthcare. Proceedings in Obstetrics and Gynecology, 2015;5(2):Article 3 [ 12 p.]. Available from: http://ir.uiowa.edu/pog/ Free full text article.

Corresponding author: Anthony P. Berger, MPH, Roy J. and Lucille A. Carver College of Medicine, University of lowa, 375 Newton Rd, lowa City, lowa 52242, anthony-berger@uiowa.edu

Financial Disclosure: The authors report no conflict of interest.

Copyright: (c) 2015 Berger et al. This is an open-access article distributed under the terms of the Creative Commons Attribution License, which permits unrestricted use, distribution, and reproduction in any medium, provided the original author and source are credited. 
birth, but identify with a masculine experience of gender. $^{2}$ Historically, a transman desiring medical means to affirm their gender has been referred to as a "female-to-male (FTM) transsexual." However, this designation reflected a binary gender system prior to the evolution of newly defined nonbinary gender identities. ${ }^{3}$ The terms transman or trans* masculine allows for a diversity of experience within the community that at times includes the molding of the female/male gender binary into a gender spectrum.

To reflect this increased variability, many trans* individuals have adopted the term "affirm", as opposed to "transition", as it more accurately conveys a sense of becoming one's true self, as opposed to changing who one is. ${ }^{2}$ The gender affirming process, and, by extension, the involvement of healthcare professionals, differs for each trans* individual. Cross-sex hormones, ("top"/"bottom") gender-affirming surgeries, pronoun/name changes, among other things are not a mandatory part of this process. ${ }^{4}$ Hence, the extent of medical intervention is determined by however much is required to treat an individual's gender dysphoria.

Gender dysphoria replaced the term Gender Identity Disorder in the 2013 updated fifth edition of the Diagnostic and Statistical Manual of Mental Disorders (DSM-5). The diagnosis of gender dysphoria requires the presence of chronic distress and disability that trans* individuals often experience while living as a gender inconsistent with their internal gender identity. It is important to distinguish the difference between gender dysphoria and gender nonconformity. Gender non-conformity is a non-pathologic, normal variation in gender expression; it is not always accompanied by feelings of distress or dysphoria. ${ }^{5}$

Given that not all trans* individuals undergo gender-affirming surgeries including removal of their reproductive organs, healthcare providers must remain aware of the risk factors associated with a trans* individual's biological sex (e.g., breast and cervical cancer for transmen, prostate cancer for transwomen, etc.), along with an awareness of the health-related risks specifically associated with the trans* community. Furthermore, many choose to preserve their fertility. Transmen, specifically, can discontinue testosterone treatment, which may lead to a resumption of the ovulatory process and a return of fertility. The details of pregnancy in transmen, along with the associated healthcare delivery considerations will be discussed in greater detail below.

\section{Estimates of the Trans* Population}

A meta-analysis of 12 prevalence studies found the overall calculated prevalence of "transsexualism" was 4.6 in 100,000 individuals. ${ }^{6}$ Many of the studies included in this meta-analysis, however, have been criticized for using inadequate surrogate variables. In response to these critics, one review study utilized mathematical models to account for the sampling errors, calculating that the overall prevalence of trans* individuals is likely between 1 in 500 to 1 in 2000 . $^{7}$ 
Historically, studies have calculated prevalence by varied, yet insufficient means. $^{8-11}$ Suggestions for accurately calculating prevalence would require sampling all persons in a given area with a two-part question: "what sex were you assigned at birth?" and "what gender most closely aligns with your internal sense of gender?" ${ }^{8}$ While a difficult task, an accurate estimate of the prevalence of trans* individuals is essential for the adequate allocation of resources for trans*-specific healthcare needs. ${ }^{9}$

\section{Trans* Healthcare: An Overview}

\section{Disparities}

Despite substantial efforts to address the unique healthcare needs of the trans ${ }^{*}$ population, ${ }^{5}$ disparities continue to exist. Barriers include overt social discrimination, lack of culturallycompetent healthcare, and structural/legal factors (i.e., electronic medical records (EMR), insurance claims, and legal gender status). ${ }^{9}$ These barriers are associated with higher rates of psychiatric disorders, ${ }^{10}$ suicide attempts/ideation, ${ }^{11}$ and substance abuse. ${ }^{12}$ Genetics, molecular abnormalities, and even gender identity have been excluded as causes of these increased rates; purporting that external forces, often termed minority stressors, are the principal etiology of most healthcare-related disparities. ${ }^{13}$

Adolescents and young adults in the trans* population are disproportionately more likely to experience homelessness compared to their cisgender peers. ${ }^{14}$ In addition, homeless trans* youth are exposed to a significantly greater number of health-related risks than homeless cisgender individuals. ${ }^{15}$ Disparities are also found in trans* individuals' personal relationships, reporting higher rates of intimate partner violence $(34.6 \%)$ than any other group. ${ }^{16}$

Infrastructural Healthcare Inadequacies for the Care of Trans* Individuals

Social discrimination and minimal effort to provide culturally competent care has resulted in an infrastructure that is logistically unsuited for high-quality healthcare for trans* individuals. The World Professional Association for Transgender Health (WPATH), along with many other professional organizations, has highlighted and elaborated upon the inequity in care for the trans* population, and provided recommendations to address those inequities. ${ }^{2,5}$ In an attempt to make the implementation of these recommendations more realistic for healthcare organizations, many actionable guidelines have been published. ${ }^{17-19}$

Additionally, federal law provides support for addressing the needs of trans* patients, and individual states are following this lead. Section 1101 of the Patient Protection and Affordable Care Act (PPACA, i.e., "Obamacare") mandates insurers to cover the treatment of gender dysphoria through the elimination of denying coverage based upon pre-existing conditions. ${ }^{20}$ In 2013, Congress amended the federal code to mandate that all federally funded healthcare practitioners ensure trans* individuals are both receiving and getting insurance coverage for necessary preventive/screening 
procedures. $^{21}$ In May of 2014, the Department of Health and Human Services eliminated the automatic exclusion of gender-affirming surgery for Medicare beneficiaries to treat gender dysphoria. ${ }^{22}$ As of August 2015, there are 6 states plus the district of Columbia that both ban insurance exclusion for transgender healthcare and provides transgender inclusive benefits for state employees. ${ }^{23}$

With increasing insurance coverage and federal support for trans* care, it is critically important for primary care and Ob-Gyn providers to be aware of a patient's trans* identity regardless of whether gender identity is openly discussed during the patient-provider interaction. Unfortunately, the EMR may not make that information readily known. Logistically, EMRs across institutions differ vastly, but few make the adjustments necessary to accommodate trans* individuals. ${ }^{24} \mathrm{~A}$ patient's legal gender is typically reflected in the medical record and oftentimes one of the demographic variables which determines certain functionalities. For trans* patients, this attempt to make the EMR more streamlined and less cumbersome, often results in obstructed access to key EMR features such as prostate screening for transwomen or obstetric care for transmen.

Recalcitrant discrimination and cultural insensitivity is the other chief fundamental barrier to providing highquality healthcare for trans* patients. A 2011 survey of greater than 6,000 trans $^{*}$ identifying patients found that 28 percent had postponed care when sick or injured, and 33 percent had not sought preventive care due to past experiences of gender-based discrimination. ${ }^{25}$ A 2008 study of transmen found that while patients perceived preventive gynecologic care to be important, incorrect pronoun usage by medical staff and noninclusive health intake forms prevented transmen from receiving those services. ${ }^{26}$ This disengagement from healthcare results in a greater burden of morbidity for easily treatable medical problems. $^{9}$

\section{Obstetric Care for Transmen}

What We Know About Perinatal Care for Transmen

In 2009, public attention was drawn to the image of Thomas Beatie, a transgender man whose pregnancy is described in his memoir, "Labor of Love". ${ }^{27}$ There is, however, limited medical and nursing literature available describing the experience or health outcomes of pregnant transmen.

In accord with previous assumptions that all trans* persons desire to make complete anatomic "transitions" to the opposite gender, healthcare providers have historically presumed a permanent loss of fertility with the treatment of gender dysphoria. ${ }^{28}$ While this scenario holds true for some trans* patients, there are many others whose affirmed gender does not include genderaffirming surgery and thus the patient retains natal reproductive organs. The medical community has not ascertained if there are genetic, epigenetic, or molecular changes to oocytes in response to long-term testosterone therapy. It is known that testosterone treatment may reduce fertility, though it 
is unknown whether this effect is universally fully reversible if testosterone is stopped. ${ }^{29}$ Historically, recommendations have suggested that trans* individuals be offered the same opportunity to "bank" their gametes as would a fertile patient undergoing treatment for malignant disease. ${ }^{30}$ Unfortunately, oocyte banking involves ovarian stimulation and egg retrieval, which may increase gender dysphoria and is often not covered by insurance and thus may be cost prohibitive.

As the concept of gender nonconformity has become more socially accepted, so too have the number of persons with stories similar to Thomas Beatie. Transmen with varying degrees of treatment for gender dysphoria have desired and achieved pregnancy, many within six months of discontinuing testosterone therapy. ${ }^{31}$ While transmen seemingly can experience a return of fertility in addition to normal birth outcomes for pregnancies, the topic certainly deserves more investigation. Because of this lack of necessary data, it is still important to have a discussion regarding fertility preservation with gamete banking prior to initiation of testosterone in transmen.

While important to discuss fertility preservation, it is also critical to provide counseling regarding the possible ineffectiveness of testosterone as the sole method of contraception for those not desiring pregnancy. Many transmen receiving testosterone therapy stop ovulating and become amenorrheic within 3 months. However, ovulation suppression may not always occur and penile-vaginal intercourse may result in unwanted pregnancy. This may be more commonplace in trans* masculine persons identifying as gender nonbinary and desiring a more androgynous physical appearance often achieved by receiving a low dose of testosterone, or transmen who miss doses of testosterone.

While research is limited, there are a number of small studies that detail obstetric care of transmen. A 2014 web based survey of 41 pregnant trans*masculine participants highlighted the complex interplay of emotions during this period. ${ }^{31}$ Gender dysphoria was increased in some of the participants, while decreased in others. Interactions with providers varied amongst the participants, though it was notable that good interactions were marked by compassion, respect, genderappropriate language, and normalcy from the healthcare staff. Isolation was another theme that extended from limited transmen-specific resources, as well as feeling perceived lack of support. Participants also felt that the family structure was fundamentally altered in essential ways to create the patients preferred family. Some participants were apprehensive about those alterations, while others celebrated the change.

Similarly, another 2014 qualitative study details the experience of eight transmen and gender-variant gestational parents who had transitioned socially or medically before pregnancy. ${ }^{32}$ Loneliness was a theme throughout the preconception, prenatal, and postpartum periods, at times exacerbated by forced disclosure of trans* status secondary to being pregnant. Participants had varied responses to the physical changes of pregnancy, which were welcome to 
some but not all. Tension points encountered with the healthcare system included discomfort and fear while building rapport with providers, communicating with office staff, receiving inpatient care in areas where patients are expected to appear female, accessing community resources, and being referred to outside providers. Participants did not want to overhear their gender identity being disclosed or discussed inappropriately.

Postpartum transmen commonly desire to chestfeed (i.e., breastfeed) though success rates may depend on previous surgical or medical treatment. Transmen with prior history of testosterone treatment may have lower rates of successful chestfeeding. ${ }^{32}$ Surprisingly, chestfeeding may still be an option for transmen even if they have undergone male chest reconstruction. ${ }^{31}$ This new subset of patients presents a number of unique considerations for lactation consultants and postpartum nursing. ${ }^{33}$ Special attention should be paid to asking a patient's preferred anatomic terms and being ever mindful of pronouns. Additionally, it is important to be respectful of the spectrum of emotions that may be evoked by lactation in transmen, from an increase in gender dysphoria to experiencing a newfound connection with their natal bodies.

With an increasing number of transmen presenting for obstetric care, all healthcare staff involved in the peripartum period require sufficient education to create a culturally-sensitive and welcoming environment for trans* patients. No longer can assumptions be made regarding a pregnant patient's preferred pronouns, gender identity, or postpartum desire to nurse one's infant.

\section{Recommendations}

\section{Electronic Medical Records}

Transmen presenting for obstetric care and providers aspiring to provide such care are greeted by the immediate challenge of documenting the patient's pregnancy. Legal gender changes are often reflected in the EMR. This change may prevent healthcare staff from accessing features necessary to properly document obstetric care. Thus, proper documentation may require changing the patient's gender from "male" to "female," which can result in feelings of dysphoria and discomfort within the healthcare system. Similar themes exist for access to essential screening tests, as EMRs may restrict providers from ordering cervical pap smears and mammograms for patients designated as "male" in their chart.

The addition of a more detailed sex/gender component in the patient demographics area would be a proposed solution for this obstacle. This is most reliably obtained by using a twopart question regarding the patient's "assigned sex at birth" (ASAB) in addition to the patient's "self-identified gender." In this manner, a trans* person is differentiated from a cisgender person because the answer to question one differs from the answer to question two. For example, transmen will have an "ASAB: female" and may answer the question of "self-identified gender" in a variety of ways: "man," or "transman," or "non-binary." With this format, the EMR would have sufficient information 
to allow for streamlined access to necessary gender affirming-related features, in addition to features relating to the patient's ASAB.

In addition to accurate identification of a patient's sex and gender in the EMR, it is critically important to allow for documentation of preferred name. This functionality would benefit many patients, cisgender and transgender alike, who prefer to be called something different than their given name. Ideally, the preferred name as well as the patient's assigned sex at birth and selfidentified gender would be present in a visible location such as the patient header.

\section{Staff Training}

In 2015, the Fenway Institute outlined a framework for providing culturally competent care for gender minorities, highlighting appropriate language and the importance of avoiding unnecessary questions. ${ }^{2}$ In order to assure that trans* patients receive high quality obstetric care in a welcoming environment, cultural competence education must be made a priority for the entire healthcare team, from front-line staff to nurses to licensed independent providers.

To make staff more familiar with appropriate language in order to provide culturally sensitive care to pregnant transmen, and to allow time to answer questions regarding general trans* health prior to the patient's delivery, our institution conducted two brief training sessions for staff members on the labor and delivery unit and the postpartum unit. These were led by a family physician that cares for transgender patients in a specialized clinic, and a nurse-midwife.

Knowledge of Resources for Trans* Families Experiencing Pregnancy and Parenthood

Lack of resources for pregnant and post-partum trans* masculine patients may be a factor contributing to feelings of isolation in this population. ${ }^{30}$ It is prudent that providers working with trans* identified patients have knowledge about organizations available for peer and family support, mental health care including psychotherapy and on-going medical care. A list of resources, both local and national, can be found in Appendix $A$.

\section{Conclusion}

While trans* masculine patients face social and structural barriers to culturally appropriate care, obstetric providers have the opportunity and responsibility to improve individual and institutional readiness to meet the needs of trans* families in the perinatal period. Our efforts must be interdisciplinary, involving all staff who have face-to-face encounters with families, and those who can effect change of the EMR infrastructure necessary to provide safe, respectful care.

\section{References}

1. Kuper LE, Nussbaum R, Mustanski B. Exploring the diversity of gender and sexual orientation identities in an online sample of transgender individuals. J Sex Res. 2012;49(2-3):244-54. doi: 10.1080/00224499.2011.596954. Epub 2011 Jul 28. PubMed PMID: 21797716. 
2. National LGBT Health Education Center. Providing welcoming services and care for LGBT people: a learning guide for health care staff. Boston, MA: The Fenway Institute; 2015. 33 p. available from: http://www.lgbthealtheducation.org/wpcontent/uploads/Learning-Guide.pdf

3. Klein K, Holtby A, Cook K, Travers R. Complicating the coming out narrative: becoming oneself in a heterosexist and cissexist world. J Homosex. 2015;62(3):297-326. doi: 10.1080/00918369.2014.970829. Epub 2014 Nov 3. PubMed PMID: 25265379.

4. Scheim Al, Bauer GR. Sex and gender diversity among transgender persons in Ontario, Canada: results from a respondent-driven sampling survey. J Sex Res. 2015;52(1):1-14. doi: 10.1080/00224499.2014.893553. Epub 2014 Apr 21. PubMed PMID: 24750105.

5. Coleman E et al. Standards of care for the health of transsexual, transgender, and gender-nonconforming people, version 7. International Journal of Transgenderism. 2012. 13(4):165-232. DOI:10.1080/15532739.2011.700873

6. Arcelus J, Bouman WP, Van Den Noortgate W, Claes L, Witcomb G, Fernandez-Aranda F. Systematic review and meta-analysis of prevalence studies in transsexualism. Eur Psychiatry. 2015 May 25. pii: S0924-9338(15)00091-7. doi: $\quad$ 10.1016/j.eurpsy.2015.04.005. [Epub ahead of print] PubMed PMID: 26021270.

7. Olyslager F, Conway L. On the calculation of the prevalence of transsexualism. Presented at 20th International Symposium, World Professional Association for Transgender Health; 5-8 September 2007; Chicago, IL. Available from: http://ai.eecs.umich.edu/people/conway/ TS/Prevalence/Reports/Prevalence $\% 20$ of\%20Transsexualism.pdf. Retrieved 22 April 2010
8. Baumle AK. International handbook on the demography of sexuality. New York: Springer; 2013.

9. Institute of Medicine(US). The health of lesbian, gay, bisexual, and transgender people: building a foundation for better understanding. Washington, DC : National Academies Press (US); 2011.

10. McLaughlin KA, Hatzenbuehler ML, Keyes KM. Responses to discrimination and psychiatric disorders among Black, Hispanic, female, and lesbian, gay, and bisexual individuals. Am J Public Health. 2010 Aug;100(8):1477-84. doi: 10.2105/AJPH.2009.181586. Epub 2010 Jun 17. PubMed PMID: 20558791.

11. Clements-Nolle $\mathrm{K}$, Marx R, Katz $\mathrm{M}$. Attempted suicide among transgender persons: The influence of gender-based discrimination and victimization. J Homosex. 2006;51(3):53-69. http://dx.doi.org/10.1300/J082v51n03_0 4 PubMed PMID: 17135115.

12. Hughes TL, Eliason, M. Substance use and abuse in lesbian, gay, bisexual and transgender populations. Journal of Primary Prevention. 2002 Mar;22(3):263-298. doi:10.1023/A:1013669705086.

13. Hatzenbuehler ML, McLaughlin KA, Keyes KM, Hasin DS. The impact of institutional discrimination on psychiatric disorders in lesbian, gay, and bisexual populations: a prospective study. Am J Public Health. 2010 Mar;100(3):452-9. doi: 10.2105/AJPH.2009.168815. Epub 2010 Jan 14. PubMed PMID: 20075314.

14. Keuroghlian AS, Shtasel D, Bassuk EL. Out on the street: a public health and policy agenda for lesbian, gay, bisexual, and transgender youth who are homeless. Am J Orthopsychiatry. 2014;84(1):66-72. doi: 10.1037/h0098852. PubMed PMID: 24826829. 
15. Cochran BN, Stewart AJ, Ginzler JA, Cauce AM. Challenges faced by homeless sexual minorities: comparison of gay, lesbian, bisexual, and transgender homeless adolescents with their heterosexual counterparts. Am J Public Health. 2002 May;92(5):773-7. http://dx.doi.org/10.2105/AJPH.92.5.773 PubMed PMID: 11988446.

16. Ard KL, Makadon HJ. Addressing intimate partner violence in lesbian, gay, bisexual, and transgender patients. J Gen Intern Med. 2011 Aug;26(8):930-3. doi: 10.1007/s11606-011-1697-6. Epub 2011 Mar 30. PubMed PMID: 21448753.

17. Alper J, Feit MN, Sanders JQ. Collecting sexual orientation and gender identity data in electronic health records: workshop summary. Institute of Medicine (US) Board on the Health of Select Populations. Washington, DC: National Academies Pres; 2013.

18. Cahill S, Makadon H. Sexual orientation and gender identity data collection in clinical settings and in electronic health records: a key to ending LGBT health disparities. LGBT Health. 2014 Mar; 1(1): 34-41. doi:10.1089/lgbt.2013.0001.

19. Deutsch MB, Green J, Keatley J, Mayer G, Hastings J, Hall AM; World Professional Association for Transgender Health EMR Working Group. Electronic medical records and the transgender patient: recommendations from the World Professional Association for Transgender Health EMR Working Group. J Am Med Inform Assoc. 2013 Jul-Aug;20(4):700-3. doi: 10.1136/amiajnl-2012-001472. Epub 2013 Apr 30. PubMed PMID: 23631835.

20. Patient Protection and Affordable Care Act of 2010, Pub. L. 111-148, Sect. 1101 (May 24, 2010).

21. Coverage of preventive health services, 29 C.F.R. Sect. 2590.715-2713 (2013).
22. Decision No. 2576 at 2, Department of Health and Human Services, Appellate Division, May 30, 2014.

23. Human Rights Campaign. Maps of State Laws \& Policies, <http://www.hrc.org/state_maps>

(2015).

24. Bauer GR, Hammond R, Travers R, Kaay M, Hohenadel KM, Boyce M. "I don't think this is theoretical; this is our lives": how erasure impacts health care for transgender people. J Assoc Nurses AIDS Care. 2009 Sep-Oct;20(5):348-61. doi: $\quad$ 10.1016/j.jana.2009.07.004. PubMed PMID: 19732694.

25. Grant JM, Mottet LA, Tanis J, Harrison $\mathrm{J}$, Herman JL, Keisling $M$. Injustice at every turn: a report of the national transgender discrimination survey. Washington: National Center for Transgender Equality and National Gay and Lesbian Task Force; 2011. Available from: http://endtransdiscrimination.org/PDFs/ NTDS_Report.pdf

26. Dutton L, Koenig K, Fennie K. Gynecologic care of the female-to-male transgender man. J Midwifery Womens Health. 2008 Jul-Aug;53(4):331-7. doi: 10.1016/j.jmwh.2008.02.003. PubMed PMID: 18586186.

27. Beatie T. Labor of love: the story of one man's extraordinary pregnancy. Berkeley, CA: Seal Press; 2008.

28. Wierckx K, Van Caenegem E, Pennings G, Elaut E, Dedecker D, Van de Peer F, Weyers S, De Sutter P, T'Sjoen G. Reproductive wish in transsexual men. Hum Reprod. 2012 Feb;27(2):483-7. doi: 10.1093/humrep/der406. Epub 2011 Nov 28. PubMed PMID: 22128292. 
29. Fertility issues. San Francisco: center of excellence for Transgender health, University of California, San Francisco; 2015. Available from: http://transhealth.ucsf.edu/trans?page $=p$ rotocol-fertility.

30. De Sutter P. Gender reassignment and assisted reproduction: present and future reproductive options for transsexual people. Hum Reprod. 2001 Apr;16(4):612-4.

http://dx.doi.org/10.1093/humrep/16.4.6

12 PubMed PMID: 11278204.

31. Light AD, Obedin-Maliver J, Sevelius JM, Kerns JL. Transgender men who experienced pregnancy after female-tomale gender transitioning. Obstet Gynecol. 2014 Dec;124(6):1120-7. doi: 10.1097/AOG.0000000000000540.

PubMed PMID: 25415163.
32. Ellis SA, Wojnar DM, Pettinato $M$. Conception, pregnancy, and birth experiences of male and gender variant gestational parents: it's how we could have a family. J Midwifery Womens Health. 2015 Jan-Feb;60(1):62-9. doi: 10.1111/jmwh.12213. Epub 2014 Sep 5. PubMed PMID: 25196302.

33. Wolfe-Roubatis E, Spatz DL. Transgender men and lactation: what nurses need to know. MCN Am J Matern Child Nurs. 2015 JanFeb;40(1):32-8. doi: 10.1097/NMC.0000000000000097. PubMed PMID: 25503832. 


\section{Appendix A}

A Guide to Health Related Resources for Trans* Patients and Families

\section{PEER SUPPORT}

\section{Local (lowa City, IA)}

- UI TransAlliance: working to make the University of lowa a welcoming place for all trans and nonbinary individuals and raise awareness of trans and nonbinary issues on campus and within the community. Website: www.facebook.com/uitransalliance

- Trans*Verse: a support group for trans people and their allies. We work to extend across feelings of isolation and confusion to the connections that can grow through community. Website: www.facebook.com/groups/TransVerselC/

\section{National}

- Gender Odyssey: an international conference focused on the needs and interests of transgender and gender-nonconforming people. Website: www.genderodyssey.org

- Philadelphia Trans-Health Conference: a program of Mazzoni Center. This FREE conference offers three full days of workshops and activities focused on the health and well-being of transgender people and our communities. Website: www.trans-health.org

\section{MENTAL HEALTH CARE}

\section{Local (lowa City, IA)}

- University of lowa LGBTQ Clinic in Department of Rehabilitation and Counseling Education (RCE): providing comprehensive clinical and consultation services for LGBTQ persons, their partners, and their families. Website: www.education.uiowa.edu/rce/family 


\section{MEDICAL CARE}

\section{Local (lowa City, IA)}

- University of lowa LGBTQ Clinic: providing full-service health care to meet the LGBTQ health care needs of patients age 10 and above. Website: www.uilgbtqclinic.com

\section{National}

- University of California San Francisco Primary Care Protocol for Transgender Patient Care: providing accurate peer reviewed medical guidance for health care practitioners providing care to trans* individuals. Website: www.transhealth.ucsf.edu/trans?page= $=$ protocol-00-00 